Contract No. and Disclaimer:

This manuscript has been authored by Savannah River Nuclear Solutions, LLC under Contract No. DE-AC09-08SR22470 with the U.S. Department of Energy. The United States Government retains and the publisher, by accepting this article for publication, acknowledges that the United States Government retains a non-exclusive, paid-up, irrevocable, worldwide license to publish or reproduce the published form of this work, or allow others to do so, for United States Government purposes. 


\title{
ASSESSMENT OF THE RADIONUCLIDE COMPOSITION OF "HOT PARTICLES" SAMPLED IN THE CHERNOBYL NUCLEAR POWER PLANT FOURTH REACTOR UNIT
}

\author{
Mikhail D. Bondarkov, ${ }^{*}$ Viktor A. Zheltonozhsky, ${ }^{\dagger}$ Maryna V. Zheltonozhskaya, ${ }^{\dagger}$ \\ Nadezhda V. Kulich, ${ }^{\dagger}$ Andrey M. Maksimenko, Eduardo B. Farfán, ${ }^{*}$ \\ G. Timothy Jannik, ${ }^{\ddagger}$ and James C. Marra ${ }^{*}$ \\ * Chernobyl Center for Nuclear Safety, Radioactive Waste and Radioecology, \\ International Radioecology Laboratory, 07100, Slavutych, Ukraine \\ ${ }^{\dagger}$ Institute of Nuclear Research of the National Academy of Sciences of Ukraine, Kyiv \\ 03680, Ukraine \\ \$Savannah River National Laboratory, Aiken, SC 29808, USA
}

\section{For reprints and correspondence contact:}

Eduardo B. Farfán, Ph.D.

Environmental Science and Biotechnology

Environmental Analysis Section

Savannah River National Laboratory

Savannah River Nuclear Solutions, LLC

773-42A, Room 236

Aiken, SC 29808

E-mail: Eduardo.Farfan@srnl.doe.gov

Phone: (803) 725-2257, Fax: (803) 725-7673

\section{Part of the Savannah River National Laboratory HPJ Special Issue}

October 2011 


\begin{abstract}
Fuel-containing materials sampled from within the Chernobyl Nuclear Power Plant $(\mathrm{ChNPP}) 4^{\text {th }}$ Reactor Unit Confinement Shelter were spectroscopically studied for gamma and alpha content. Isotopic ratios for cesium, europium, plutonium, americium, and curium were identified and the fuel burnup in these samples was determined. A systematic deviation in the burnup values based on the cesium isotopes, in comparison with other radionuclides, was observed. The conducted studies were the first ever performed to demonstrate the presence of significant quantities of ${ }^{242} \mathrm{Cm}$ and ${ }^{243} \mathrm{Cm}$. It was determined that there was a systematic underestimation of activities of transuranic radionuclides in fuel samples from inside of the ChNPP Confinement Shelter, starting from ${ }^{241} \mathrm{Am}$ (and going higher), in comparison with the theoretical calculations.
\end{abstract}

Key words: Chernobyl, fuel-containing materials, isotopic ratios, hot particles 


\section{INTRODUCTION}

Following the 1986 accident at the $4^{\text {th }}$ reactor unit of the Chernobyl Nuclear Power Plant (ChNPP), a large concrete sarcophagus, called the Chernobyl Confinement Shelter, was placed over the $4^{\text {th }}$ reactor unit to isolate it. Studies of "hot particles" sampled within the Confinement Shelter have recently become very important because the surfaces of the lava-like fuelcontaining materials at the leak locations are being continuously destroyed due to irradiation, spontaneously generating dozens of kilograms of finely dispersed aerosols with particle sizes ranging from 60 to $300 \mathrm{~nm}$ and containing radionuclides characteristic of irradiated nuclear fuel. Since the roof of the Confinement Shelter has openings, these aerosols contribute to contamination of the adjacent ChNPP site. To assess radioecological hazards associated with this phenomenon, isotopic ratios of radionuclides in the lava-like fuel containing materials from the Confinement Shelter need to be compared with isotopic ratios in the soil sampled in the vicinity of the ChNPP site. This is important due to the fact that, during the 1986 ChNPP accident, a large quantity of fuel-containing materials was released into the environment, including deposition on the soil. Significant migration processes occur in the soil and destruction processes occur in the sarcophagus, with ${ }^{137} \mathrm{Cs}$ and ${ }^{90} \mathrm{Sr}$ behaving differently in these processes.

In addition, cesium, europium, and plutonium isotopic ratios make it possible to assess the fuel burnup in the "hot particles." This is an essential task because no accurate assessments are available to-date on how much fuel was released during the ChNPP accident and where this fuel is located. Uncertainties in the various assessments reach $30-40 \%$. It should be noted that, in

practically every case, the burnup calculation was based on the ${ }^{134} \mathrm{Cs} /{ }^{137} \mathrm{Cs}$ ratios (Pazukhin et al. 2000). However, if xenon is present in the isotope production chain, these calculations may 
contain significant errors, because, as reported in IAEA (2006), up to $50 \%$ of the radioactivity resulting from the ChNPP accident might have been released with noble gases. Xenon is not only a noble gas, it is also an intermediate radionuclide in the formation of ${ }^{134} \mathrm{Cs}$ and ${ }^{137} \mathrm{Cs}$. Currently, the ratios of ${ }^{154,155} \mathrm{Eu}$ and plutonium isotopes are available for study, which may help increase the validity of fuel burnup calculations.

Finally, the knowledge of relative concentrations of activity of such radionuclides as ${ }^{241} \mathrm{Am}$ and ${ }^{243,244} \mathrm{Cm}$, in comparison with the plutonium isotopes, will make it possible to more accurately estimate the quantities of generated transuranic radionuclides because errors in the transuranic calculations, starting with ${ }^{241} \mathrm{Am}$, reach $40-50 \%$.

\section{EXPERIMENTAL METHODS AND RESULTS}

Fragments of fuel-containing materials from the Confinement Shelter were sampled in the locations where the main lava-like flows were observed (in the facilities located underneath the destroyed ChNPP $4^{\text {th }}$ reactor unit). Then, under laboratory conditions, "hot particles" were sampled from the fragments based on the presence of $K_{\mathrm{x}}$-irradiation of uranium and visually. A total of 24 "hot particles" were sampled. The ${ }^{134}$ Cs activity of the sampled "hot particles" ranged from $10^{4}$ to $10^{7} \mathrm{~Bq} \mathrm{~g}^{-1}$. The masses of the sampled particles ranged from several tens to several hundreds of milligrams.

The measurements were performed using a high-purity germanium (HPGe) spectrometer with a beryllium window and a volume of $2 \mathrm{~cm}^{3}$. Some of the $\gamma$-spectra were analyzed using a Compton suppression spectrometer with a HPGe detector, a beryllium window and the power resolution of $1.9 \mathrm{keV}$ for the ${ }^{60} \mathrm{Co} \gamma$-lines and $350 \mathrm{eV}$ for the $59 \mathrm{keV} \gamma$ from ${ }^{241} \mathrm{Am}$. The 
spectrometer efficiency was $30 \%$. The suppression of the Compton background at low energies was at least a factor of eight, making it possible to reliably identify the ${ }^{243} \mathrm{Am}$ activity.

Fig. 1 shows a few fragments of the measured gamma spectra in a low energy field. Since the ${ }^{134,137} \mathrm{Cs}$ and ${ }^{154,155} \mathrm{Eu}$ ratios had to be identified very accurately, specialized software was used for processing the $\gamma$-spectra. For this purpose, a code for processing complex multiple spectra was adjusted (Vishnevsky et al. 1999) as described in the following paragraphs.

To describe the shape of the peak, the Gaussian distribution with "tails" was used:

$$
f(i, \boldsymbol{\alpha})= \begin{cases}\alpha_{1} \cdot \exp \left(\frac{\alpha_{4}\left(2 i-2 \alpha_{2}+\alpha_{4}\right)}{2 \alpha_{3}^{2}}\right), & i<\alpha_{2}-\alpha_{4} \\ \alpha_{1} \cdot \exp \left(-\frac{\left(i-\alpha_{2}\right)^{2}}{2 \alpha_{3}^{2}}\right), & \alpha_{2}-\alpha_{4} \leq i \leq \alpha_{2}+\alpha_{5} \\ \alpha_{1} \cdot \exp \left(\frac{\alpha_{5}\left(2 \alpha_{2}-2 i+\alpha_{5}\right)}{2 \alpha_{3}^{2}}\right), & i>\alpha_{2}+\alpha_{5}\end{cases}
$$

Where $\alpha_{\mathrm{n}}$ are the parameters that describe the Gaussian distribution with "tails," and $i$ is the channel number.

In some cases, it was not possible to use eqn (1) to satisfactorily describe the shape of the peak. For those cases, it was manageable to generate a certain standard line, the prototype of which was a "strong" single line from the same or similar spectrum. Describing peaks of the characteristic spectrum is associated with certain methodological difficulties. The shape of the line in the peak is known to result from convolution of its own shape and the function of the spectrometer (or other instrument) response:

$$
F(E)=\int_{-\infty}^{\infty} G\left(E^{\prime}\right) D\left(E-E^{\prime}\right) d E^{\prime}
$$


The shape of the line is described by the Lorentzian function:

$$
G(E)=\frac{\Gamma / 2 \pi}{\left(E-E_{0}\right)^{2}+(\Gamma / 2)^{2}}
$$

where $E$ is the energy, $E_{0}$ is the average photon energy, and $\Gamma$ is the width of the line.

The function of the spectrometer response $D(E)$ is described in the code by eqn (1) or by the standard line. Since the width of the $\gamma$-lines is significantly less than $10^{-2} \mathrm{eV}$ and the width of the instrument line is $1 \mathrm{keV}$, the shape of the $\gamma$-line can be considered as a $\delta$-function and the shape of the line in the spectrum is fully determined by the function of the spectrometer response.

This is not the case with $\mathrm{x}$-ray lines. The $\mathrm{x}$-ray $\mathrm{K}_{\mathrm{x}}$ lines result from electron transfer from $\mathrm{L}, \mathrm{M}, \ldots$ subshells upon filling vacancies in the K-shell. The width of these lines is equal to the sum of the $\mathrm{K}$ and $\mathrm{L}, \mathrm{M}$,...levels. Data on natural widths upon excitation of $\mathrm{K}$ and $\mathrm{L}$ levels are well known and, for heavy elements, the width of the $\mathrm{K}_{\mathrm{x}}$-lines proper are $100 \mathrm{eV}$ and higher and the widths for $\mathrm{L}_{\mathrm{x}}$ transfers are $30 \mathrm{eV}$ and higher. Since the Lorentzian shape significantly differs from the shape of the instrument line that can be approximately described by a Gaussian function, their convolution results in a line, the edges of which appear "tightened" in comparison with the instrument line. In this case, if the proper shape of the line is ignored, the computational procedure will result in the uncertainties of $\sim 5 \%$ for the intensity value, which is unacceptable for achieving good statistical results and complying with the requirement not to exceed $\sim 1 \%$ uncertainty.

Therefore, for processing the x-ray peaks, the selected shape of the instrument line was convoluted with the Lorentzian of the appropriate width by numerical integration using eqn (2). The line resulted from the convolution was used as the standard line for data processing. However, in this case, the major focus was given to the selection of a shape of the lines since 
many measurements were performed when the spectrometer was overloaded, causing significant changes in the shape of the $\gamma$-lines. The software made it possible to use one of the single $\gamma$-lines as the "tabular" line. This "tabular" $\gamma$-line was entered into the studied fragment of the spectrum. Since distortions of the $\gamma$-line shape were present in both the "tabular" line and in the studied lines, the impact of the $\gamma$-line shape was automatically excluded.

The obtained spectra showed that the samples taken from within the Confinement Shelter contained ${ }^{243} \mathrm{Am}$ activity (Fig. 1). The $\gamma$-line multiplet with the energies of $3.4 \mathrm{keV}, 74.4 \mathrm{keV}$, $76.6 \mathrm{keV}$, and $77.1 \mathrm{keV}$ appeared to be present in the $70-80 \mathrm{keV}$ area. These lines were identified as a cumulative peak of the neptunium Lx-radiation and $\gamma 59 \mathrm{keV}$ : $\gamma 59+\mathrm{L} \alpha, \gamma 59 \mathrm{keV}+\mathrm{L} \beta$, $\gamma 74.67{ }^{243} \mathrm{Am}$ and the escape peak for $\gamma 86 \mathrm{keV}-\mathrm{K}_{\alpha} \mathrm{Ge}$. The number of counts in $\gamma 74.6 \mathrm{keV}$ was $9.4 \times 10^{4}$; i.e., the statistical error did not exceed $2 \%$.

Note that, if $\gamma$-spectra are measured using conventional spectrometers with lead shielding, the lead $\mathrm{K} \alpha$-irradiation is always present in the $\gamma$-spectrum. The $\mathrm{K}_{\alpha}$-group energies are equal to 72.8 and $75.0 \mathrm{keV}$, i.e., $\mathrm{K} \alpha_{1}$, within the energy resolution of the spectrometers in this area, is not separated from $\gamma 74.7 \mathrm{keV}$ of ${ }^{243} \mathrm{Am}$ and this fact primarily explains why no valid data on ${ }^{243} \mathrm{Am}$ are available from measurements using conventional spectrometers.

The system with the Compton suppression spectrometer uses a combined shielding resulting in a practical non-existence of $\mathrm{K}_{\alpha} \mathrm{Pb}$. The number of counts during $5-6 \mathrm{~d}$ in the $75 \mathrm{keV}$ area does not exceed $(3-5) \times 10^{3}$. The $\gamma$-spectrum of this particle was measured during approximately the same period of time. Some of the samples were measured using the HPGe detector with a beryllium window and a volume of $2 \mathrm{~cm}^{3}$ (Fig. 2) where the $\mathrm{K}_{\alpha} \mathrm{Pb}$ contribution was observed. However, it is easy to account for this contribution if it is assumed that $\mathrm{K}_{\alpha 1} \mathrm{~Pb}$ is $46 \%$ and $\mathrm{K}_{\alpha 2}$ is $28 \%$. 
Radiochemical analyses also were performed. For this purpose, the "hot particles" were first treated with concentrated $\mathrm{HF}, \mathrm{HNO}_{3}$ and $\mathrm{HCl}$ in a Teflon ${ }^{\circledR}$ can to transfer the radionuclides into the solution. After the "hot particles" were completely dissolved, the generated solution was evaporated, resulting in wet salts. Using the method of direct $\alpha$-spectroscopy (Lashko et al. 2001), the isotopic composition of $\alpha$-emitters was obtained. To obtain the isotopic composition, electrolytic precipitation of the radionuclides was performed on a stainless steel disk. Alpha Analyst Integrated Alpha Spectrometers ${ }^{\S}$ were utilized for these measurements. Fig. 3 shows the obtained spectrum. This method made it possible to assess the isotopic composition of $\alpha$-emitters in the "hot particles", showing ${ }^{234,235,236,238} \mathrm{U},{ }^{236,239,240,241} \mathrm{Pu},{ }^{238} \mathrm{Pu},{ }^{241} \mathrm{Am},{ }^{243} \mathrm{Am}$, and ${ }^{242-244} \mathrm{Cm}$ in the sample.

Using the obtained data on the isotopic composition, radiochemical analyses were performed that made it possible to divide the uranium, plutonium, americium, and curium isotopes and to assess the activity in the sample. The radiochemical analysis included the following phases:

1. Sample an aliquot of the "hot particles" solution;

2. Introduce carriers and tracers;

3. Separate uranium, plutonium, americium, and curium using the UTEVA $\AA^{* *}$ ion exchange resin;

4. Separate americium and curium from the alkaline metals with calcium oxalate; and

5. Separate americium and curium isotopes from ${ }^{90} \mathrm{Sr}$ using the TRU ${ }^{\dagger \dagger}$ ion exchange resin. 
Figs. $4-6$ show the $\alpha$-spectra of the corresponding $\alpha$-nuclides. All the above mentioned activity appeared to be reliably recorded. Table 1 provides the data for one of the "hot particles" that was studied by both radiochemical and gamma spectrometry methods. The burnup data analysis showed that the sampled "hot particles" had the same burnup within $10 \%$ error, and, consequently, their radionuclide composition should be approximately the same. This fact was experimentally confirmed.

\section{DISCUSSION AND CONCLUSIONS}

Burnup is an important characteristic of spent nuclear fuel that makes it possible to assess the extent of use of uranium and other fissile isotopes in spent nuclear fuel, as well as the quantity of fission and transuranic fragments that accumulated in the reactor during one reactor campaign. Regarding the fuel in the destroyed ChNPP $4^{\text {th }}$ reactor unit, the burnup value is one of the defining values for calculating the sub-criticality of individual conglomerates of fuel containing masses. In other words, the burnup value makes it possible to assess overall nuclear criticality safety of the Confinement Shelter. Moreover, comparison of the burnup values in various types of Chernobyl lavas sheds light on the homogenization of these lavas while spreading in the sub-reactor facilities, thereby making it possible to assess the probability of various potential scenarios associated with the active phase of the ChNPP accident.

Reviews of the data in the existing literature show that, in most cases, fuel burnup in the samples obtained within the Confinement Shelter and in the surrounding ChNPP proximity zone was calculated using the results of the gamma spectrometric analysis; specifically, the ${ }^{134} \mathrm{Cs} /{ }^{137} \mathrm{Cs}$ ratio (Pazukhin et al. 2000). Scientists have been debating whether it is appropriate to use the ${ }^{134} \mathrm{Cs} /{ }^{137} \mathrm{Cs}$ ratio for determining the nuclear fuel burnup because these cesium isotopes 
originate from various predecessors during fission of uranium nuclei (Borovoj et al. 2000). ${ }^{137} \mathrm{Cs}$ originates from the fission products based on the beta-decay chain, and the last member of this chain is ${ }^{137} \mathrm{Xe} .{ }^{134} \mathrm{Cs}$ originates from stable ${ }^{133} \mathrm{Cs}$ by neutron capture:

$$
\begin{aligned}
& { }^{137} \mathrm{I}(\mathrm{FP}) \stackrel{24.5 \mathrm{~s}}{\mathrm{\beta}}{ }^{137} \mathrm{Xe} \stackrel{3.82 \mathrm{~min}}{\beta}{ }^{137} \mathrm{Cs} \stackrel{30 \mathrm{y}}{\longrightarrow}{ }^{137} \mathrm{Ba}(\text { stable) ; } \\
& { }^{133} \mathrm{Sb}(\mathrm{FP}) \stackrel{2.36 \mathrm{~min}}{\beta}{ }^{133} \mathrm{Te} \stackrel{12.4 \mathrm{~min}}{\beta}{ }^{133} \mathrm{I} \stackrel{20.8 \mathrm{~h}}{\longrightarrow}{ }^{133} \mathrm{Xe} \stackrel{.5 .24 \mathrm{~d}}{\longrightarrow} \\
& { }^{133} \mathrm{Cs} \text { (stable) } \underset{\mathrm{n}, \gamma}{\longrightarrow}{ }^{134} \mathrm{Cs} \stackrel{2,062 \mathrm{y}}{\longrightarrow}{ }^{134} \mathrm{Ba} \text { (stable) }
\end{aligned}
$$

where FP is fission product and the half-lives are taken from Firestone et al. (1996).

Therefore, elements with different chemical and physical properties, such as cesium and xenon, may or may not be similarly deployed in regular locations of the $\mathrm{UO}_{2}$ lattice; having varying volatility, they may or may not behave similarly under the extreme conditions of the ChNPP accident. In view of the above, ${ }^{134} \mathrm{Cs} /{ }^{137} \mathrm{Cs},{ }^{154} \mathrm{Eu} /{ }^{155} \mathrm{Eu}$, and ${ }^{238} \mathrm{Pu} /{ }^{238,240} \mathrm{Pu}$ ratios were used to determine and compare burnup values in typical lava-like fuel containing materials using various independent methods.

The following equations (Borovoj and Pazukhin 2003) were used to calculate the burnup (B):

$$
\left.\begin{array}{l}
\mathrm{B}(\mathrm{Cs})=24.2\left[\mathrm{~A}\left({ }^{134} \mathrm{Cs}\right) / \mathrm{A}\left({ }^{137} \mathrm{Cs}\right)\right]-1.21 \\
\mathrm{~B}(\mathrm{Eu})=30.1\left[\mathrm{~A}\left({ }^{154} \mathrm{Eu}\right) / \mathrm{A}\left({ }^{155} \mathrm{Eu}\right)\right]-11.1 \\
\mathrm{~B}(\mathrm{Pu})=-4.12\left[\mathrm{~A}\left({ }^{238} \mathrm{Pu}\right) / \mathrm{A}\left({ }^{238,240} \mathrm{Pu}\right)\right]^{2}+18.22\left[\mathrm{~A}\left({ }^{238} \mathrm{Pu}\right) / \mathrm{A}\left({ }^{238,240} \mathrm{Pu}\right)\right]+4.991
\end{array}\right\}
$$

where $\mathrm{B}$ is burnup, MW·day $\mathrm{kg}^{-1}$ of $\mathrm{U}$, and $\mathrm{A}$ is the activity of corresponding isotopes calculated for 26 April 1986.

It is necessary to convert the burnup value expressed in $\mathrm{kg}$ per ton of uranium into $\mathrm{MW} \cdot$ day $\mathrm{kg}^{-1}$ of $\mathrm{U}$, with the latter being calculated using the $\mathrm{M}\left(\mathrm{N}_{\mathrm{A}} \mathrm{E} \times 10^{3}\right)^{-1}$ coefficient where 
$\mathrm{M}$ is an average molar mass of fissile nuclei, $\mathrm{N}_{\mathrm{A}}$ is Avogadro's number, and $\mathrm{E}$ is an average energy release for one fission reaction (Pazukhin 2003).

The RBMK-1000 ChNPP reactor does not use pure ${ }^{235} \mathrm{U}$, but ${ }^{238} \mathrm{U}$ fuel with $2 \%$ enrichment. In view of the above, a complete burnup of $1 \mathrm{~kg}$ of the fuel uranium results in 18.44 MW·day of energy. Beyond that, the fuel elements contain uranium dioxide and not pure uranium, therefore, the burnup for the uranium dioxide fuel will be lower; i.e., $\mathrm{B}=16.25$ MW·day kg ${ }^{-1}$ of $\mathrm{UO}_{2}$ (Pazukhin 2003).

Table 2 contains the estimated burnup based on the studied "hot particles" with minimum (sample \#1) and maximum (sample \#2) concentrations of ${ }^{137} \mathrm{Cs}$. A systematic underestimation of the burnup (by 2 - $3 \mathrm{MW} \cdot \mathrm{day}, \mathrm{kg} \mathrm{U}$ ) based on the ${ }^{134,137} \mathrm{Cs}$ ratios is clearly observed in comparison with the europium and plutonium calculations. This fact also was observed in the samples obtained in the vicinity of the Confinement Shelter (Zheltonozhskaya 2009). This implies that the coefficients for burnup calculations based on ${ }^{134} \mathrm{Cs} /{ }^{137} \mathrm{Cs}$ ratios are lower than they should have been.

One of the reasons for this deviation may be associated with the selection of the half-life periods. Various tables provide various numbers that may differ by $3-4 \%$. Since nearly 25 years have passed since the ChNPP accident, this error could have resulted in significant systematic uncertainties. For example, the half-lives provided for ${ }^{154,155} \mathrm{Eu}$ are $\mathrm{T}_{1 / 2}=8.8 \mathrm{y}$ and $4.96 \mathrm{y}$ by Lederer and Shirlev (1978) and $\mathrm{T}_{1 / 2}=8.593 \mathrm{y}$ and $4.76 \mathrm{y}$ by Firestone et al. (1996), respectively. This discrepancy results in the adjustment factor being equal to 0.91 . Taking into account the fact that the burnup based on europium isotopes is calculated using eqn (5), it can be observed that the typical values could have been underestimated by $20 \%$; i.e. by the same $2-2.5$ units of B (burnup). This can be seen from the fact that the europium activity for 1986 was re-estimated 
using the equation $\left(1-\mathrm{e}^{\lambda t}\right) \mathrm{e}^{\lambda t}$. It is also important to obtain $\gamma$-transfer yield data from the same tables. For ${ }^{155} \mathrm{Eu}, \gamma 86 \mathrm{keV}$ in the table obtained from Lederer and Shirlev (1978) is equal to $34 \%$ and in the table obtained from Firestone et al. (1996) it is equal to $30.7 \%$; i.e., the values differ by $10-11 \%$.

To make sure that the selection of the absolute yields in ${ }^{155} \mathrm{Eu}$ is correct, the spectra of "hot particles" with the large ${ }^{155} \mathrm{Eu}$ yield were studied and the $\gamma 86 \mathrm{keV}$ yield was found equal to $30.4 \pm 0.8 \%$; i.e., it matched the data from Firestone et al (1996). Therefore, for further assessments of the burnup values, it is preferred that data from the table obtained from Firestone et al. (1996) should be used. The data on $\alpha$-emitters for other radionuclides show significant deviations from the theoretically calculated values. The theoretical value for the ${ }^{243} \mathrm{Am}$ to ${ }^{241} \mathrm{Am}$ isotopic activities ratio is $2.2 \times 10^{-3}$; it is overestimated by approximately a factor of 1.5 in comparison with the experimental data. At the same time, the comparison of the ${ }^{243}$ Am activity with the total ${ }^{239,240} \mathrm{Pu}$ activity shows that the ratio matches the theoretically calculated values within the measurements uncertainty.

This study was the first to observe ${ }^{243} \mathrm{Cm}$ activity in $\gamma$-spectra of five "hot particles", which made it possible to significantly adjust the value of the ${ }^{244} \mathrm{Cm}$ activity and its relationship with the ${ }^{239,240} \mathrm{Pu}$ yield. In this case, the experimental value appeared to be underestimated in comparison with the theoretically calculated values, but, unlike ${ }^{243} \mathrm{Am}$, by factors of $3-5$ lower, depending on the burnup. In the $\alpha$-spectrum, transfers belonging to ${ }^{242} \mathrm{Cm}$ decay were observed. Considering the fact that ${ }^{242} \mathrm{Cm}$ has a relatively short half-life $\left(\mathrm{T}_{1 / 2}=162 \mathrm{~d}\right)$, it can be concluded that its longer-lived parent, ${ }^{242} \mathrm{Am}\left(\mathrm{T}_{1 / 2}=141 \mathrm{y}\right)$, is observed.

Finally, attention is drawn to the ${ }^{90} \mathrm{Sr}$ and ${ }^{137} \mathrm{Cs}$ ratio. This ratio is significantly different from the 1986 data for the fuel component. The ${ }^{90} \mathrm{Sr}$ yield in the measurements is overestimated 
by factors of $4-5$. The initial ${ }^{90} \mathrm{Sr} /{ }^{137} \mathrm{Cs}$ ratio in the fuel from the ChNPP $4^{\text {th }}$ reactor unit was approximately 0.5 . Due to a high velocity of ${ }^{90} \mathrm{Sr}$ migration in the soils of the CHNPP proximity zone in comparison with the ${ }^{137} \mathrm{Cs}$ migration, this ratio may only decrease as a function of time. However, we observe the reverse situation in samples taken from within $5 \mathrm{~km}$ of the ChNPP: in some areas, the value of the ${ }^{90} \mathrm{Sr} /{ }^{137} \mathrm{Cs}$ ratio significantly exceeds the initial ratio. This may appear to be a very convenient way for evaluating the role of "fresh" fallout in the soils adjacent to the Confinement Shelter. For this purpose, it is sufficient to measure the $\mathrm{A}\left({ }^{90} \mathrm{Sr}\right) / \mathrm{A}\left({ }^{137} \mathrm{Cs}\right)$ ratio in the sampled soils taken from the surface and depth and compare it with the obtained data for the "hot particles" sampled in the middle of the Confinement Shelter. The data on radionuclide transport in the soils of the adjacent territories (Bondarkov et al. 2006) show that, currently, the $T_{1 / 2}$ periods of environmental half-life for the upper $5 \mathrm{~cm}$ deep soil layers in the ChNPP proximity zone are practically the same for ${ }^{90} \mathrm{Sr}$ and ${ }^{137} \mathrm{Cs}$. Therefore, a significant difference of the radionuclides in the "hot particles" from the Confinement Shelter will make it possible to obtain a quantitative assessment of the role of the "fresh" fallout.

The conducted studies were the first ever performed to demonstrate the presence of significant quantities of ${ }^{242} \mathrm{Cm}$ and ${ }^{243} \mathrm{Cm}$. The authors found a systematic underestimation of activities of transuranic radionuclides in fuel samples from within the ChNPP Confinement Shelter, starting from ${ }^{241} \mathrm{Am}$, in comparison with the theoretical calculations. A new method of measurements of ${ }^{134} \mathrm{Cs}$ and ${ }^{137} \mathrm{Cs}$ gamma spectra coincidence for burnup calculations was proposed. This new method for measuring the isotopic ${ }^{134} \mathrm{Cs}$ and ${ }^{137} \mathrm{Cs}$ ratio is based on the fact that, currently, the ${ }^{134} \mathrm{Cs}$ contribution does not exceed a few tenths of one percent, in comparison with ${ }^{137} \mathrm{Cs}$. However, this difficulty can be easily overcome by using a simple gamma-gamma coincidence system with a large size NaI (Tl) detector and a HPGe detector. The ${ }^{134} \mathrm{Cs}$ decay 
mainly progresses by a cascade of two gamma transitions with the energies of 604 and $796 \mathrm{keV}$. Therefore, in such a system, in integral coincidences, the $661 \mathrm{keV}$ gamma intensity will be suppressed by a factor of a few hundreds, while the $604 \mathrm{keV}$ gamma intensity will be suppressed no more than by factors of 2 or 3 , depending on the NaI (Tl) detector size. To illustrate this methodology, we measured current ${ }^{134,137} \mathrm{Cs}$ activities. Fig. 7 shows the obtained spectra. The ${ }^{134} \mathrm{Cs}$ activity can be easily separated in the coincidence spectrum.

Acknowledgments - The authors would like to thank Ines Triay, Yvette Collazo, Kurt Gerdes, and Ana Han for their support of the U.S. Department of Energy Office of Environmental Management's International Cooperative Program with IRL. The authors would also like to express their gratitude to Tatyana Albert (Thomas E. Albert and Associates, Inc.) for translating documents and reports prepared at SRNL and IRL, and Elizabeth LaBone for editing this article.

Disclaimer - This manuscript has been co-authored by Savannah River Nuclear Solutions, LLC under Contract No. DE-AC09-08SR22470 with the U.S. Department of Energy. The United States Government retains and the publisher, by accepting this article for publication, acknowledges that the United States Government retains a non-exclusive, paid-up, irrevocable, worldwide license to publish or reproduce the published form of this work, or allow others to do so, for United States Government purposes. Mention of trade names or commercial products does not constitute endorsement or recommendation for use by the authors or their corresponding organizations. 


\section{REFERENCES}

Bondarkov MD, Gaschak SP, Zheltonozhskaya MV et al. Vertical migration of radionuclides in the area of Chernobyl test sites. Problems of safety of nuclear power plants in Chernobyl (6):155-163; 2006.

Borovoj AA, Pazukhin EM. Ratios of plutonium isotopes depending on the nuclear fuel burnup. Radiokhimiya 45(2):191-192; 2003.

Firestone RB, Shirlev VS, Baglin CM et al. The 8th edition of the Table of Isotopes. CD-ROM. Ver.1; 1996.

International Atomic Energy Agency. The Chernobly Forum: 2002-2005, IAEA/PI/A.87 rev. 2, 06-09181; Austria: IAEA; 2006.

Lashko AP. Comprehensive analysis of plutonium isotopic composition in the accidental release of the ChNPP $4^{\text {th }}$ reactor unit. Atomnaya Energiya. 91(6):443-448; 2001.

Lederer C, Shirlev VS, Table of Isotopes. New York; 1978.

Pazukhin EM, Makarova TP, Stepanov AV, Belyaev BN. Regarding burnup of nuclear fuel. Radiokhimiya. 42(6):527-532; 2000.

Vishnevsky IN, Zheltonozhsky VA, Zelinsky AM. Atomic nuclear effects in processes of internal conversion of gamma rays. Collection of Scientific Articles of the Institute of Nuclear Research, Kiev, 60-64; 1999.

Zheltonozhskaya, MV. Studies of isotopic ratios in soil layers of the ChNPP 5-km zone. Yadernaya Fizika i Energetika 10(4):409-412; 2009. 


\section{FOOTNOTES}

* Chernobyl Center for Nuclear Safety, Radioactive Waste and Radioecology, International Radioecology Laboratory, 07100, Slavutych, Ukraine

${ }^{\dagger}$ Institute of Nuclear Research of the National Academy of Sciences of Ukraine, Kyiv 03680, Ukraine

$\$$ Savannah River National Laboratory, Aiken, SC 29808, USA

$\S$ The web link for Canberra's Alpha Analyst Integrated Alpha Spectrometer is http://www.canberra.com/products/696.asp

${ }^{* *}$ UTEVA ${ }^{\circledR}$ Resin can be purchased at http://www.eichrom.com/products/info/uteva resin.cfm

$\dagger$ TRU Resin can be purchased at http://www.eichrom.com/products/info/tru_resin.cfm 


\section{FIGURE CAPTIONS}

Fig. 1. Fragment of a gamma spectrum measured using a Compton suppression spectrometer.

Fig. 2. Fragment of a gamma spectrum measured using an x-ray spectrometer.

Fig. 3. a) Total alpha spectrum. b) Fragment of the total alpha spectrum. Area of uranium and ${ }^{242} \mathrm{Pu}$. c) Fragment of the total alpha spectrum. ${ }^{243,}{ }^{244} \mathrm{Cm}$.

Fig. 4. Alpha spectrum of uranium isotopes after separation using the UTEVA ion exchange resin.

Fig. 5. Alpha spectrum of plutonium isotopes after separation using UTEVA ion exchange resin.

Fig. 6. Alpha spectrum of americium and curium after separation using UTEVA and TRU ion exchange resins.

Fig. 7. Fragments of the Samples Gamma Spectra Obtained by Using the Gamma Gamma Coincidence System with a Large NaI (Tl) Detector and a HPGe Detector (a - single spectrum, b - coincidence spectrum). 


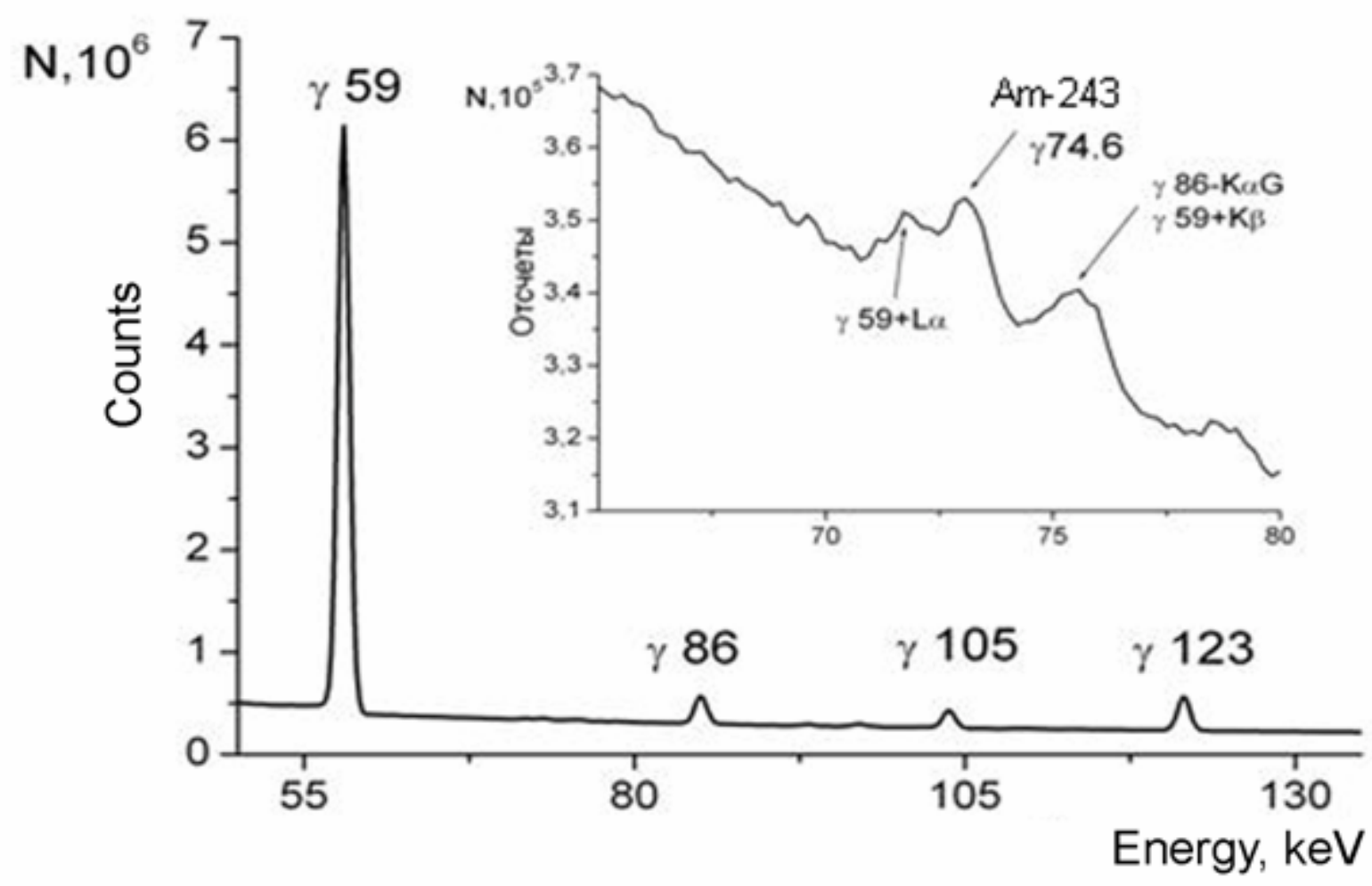

Fig. 1. Fragment of a gamma spectrum measured using a Compton suppression spectrometer. 




Fig. 2. Fragment of a gamma spectrum measured using an x-ray spectrometer. 

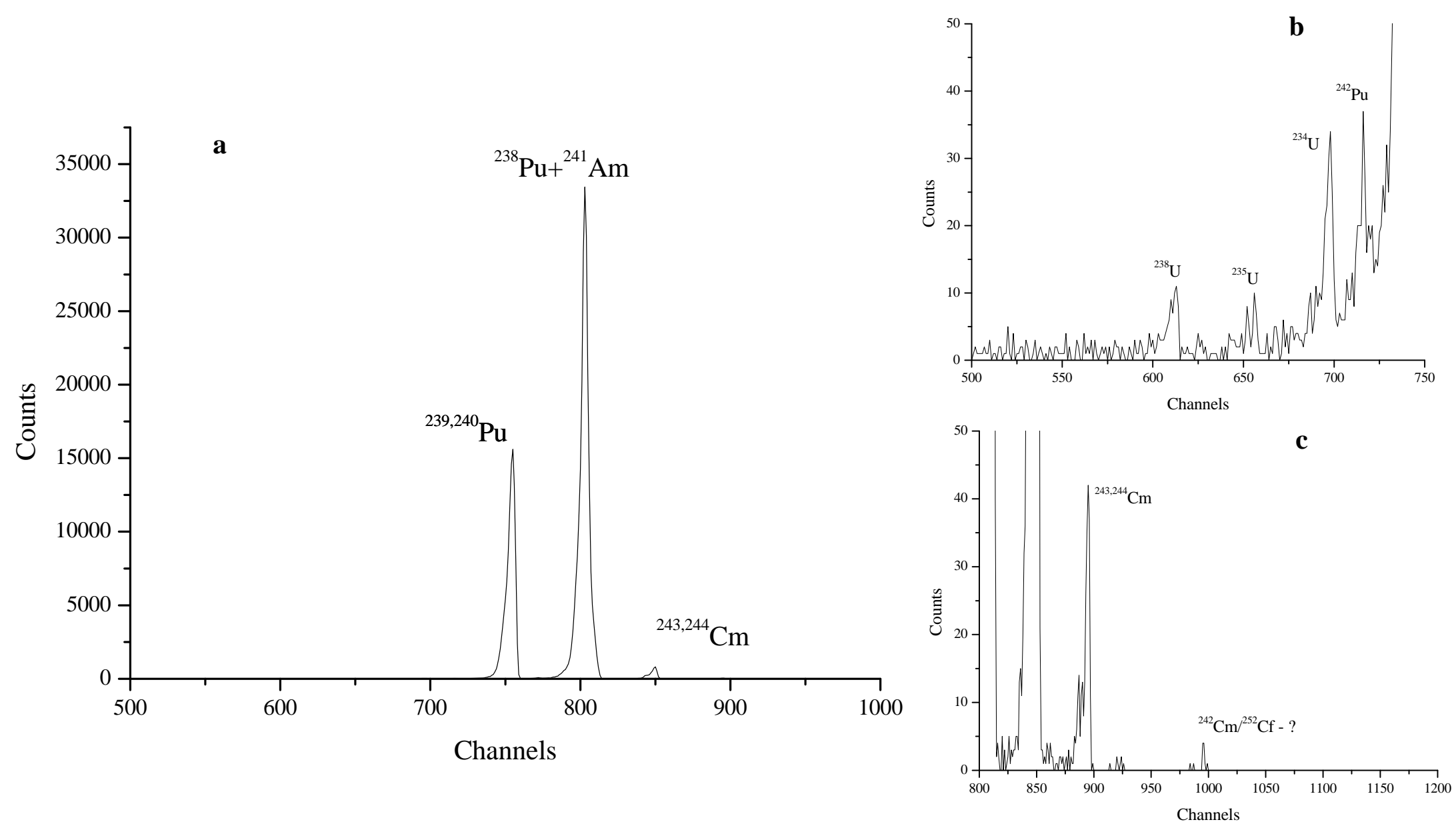

Fig. 3. a) Total alpha spectrum. b) Fragment of the total alpha spectrum. Area of uranium and ${ }^{242} \mathrm{Pu}$. c) Fragment of the total alpha spectrum. ${ }^{243,}{ }^{244} \mathrm{Cm}$. 


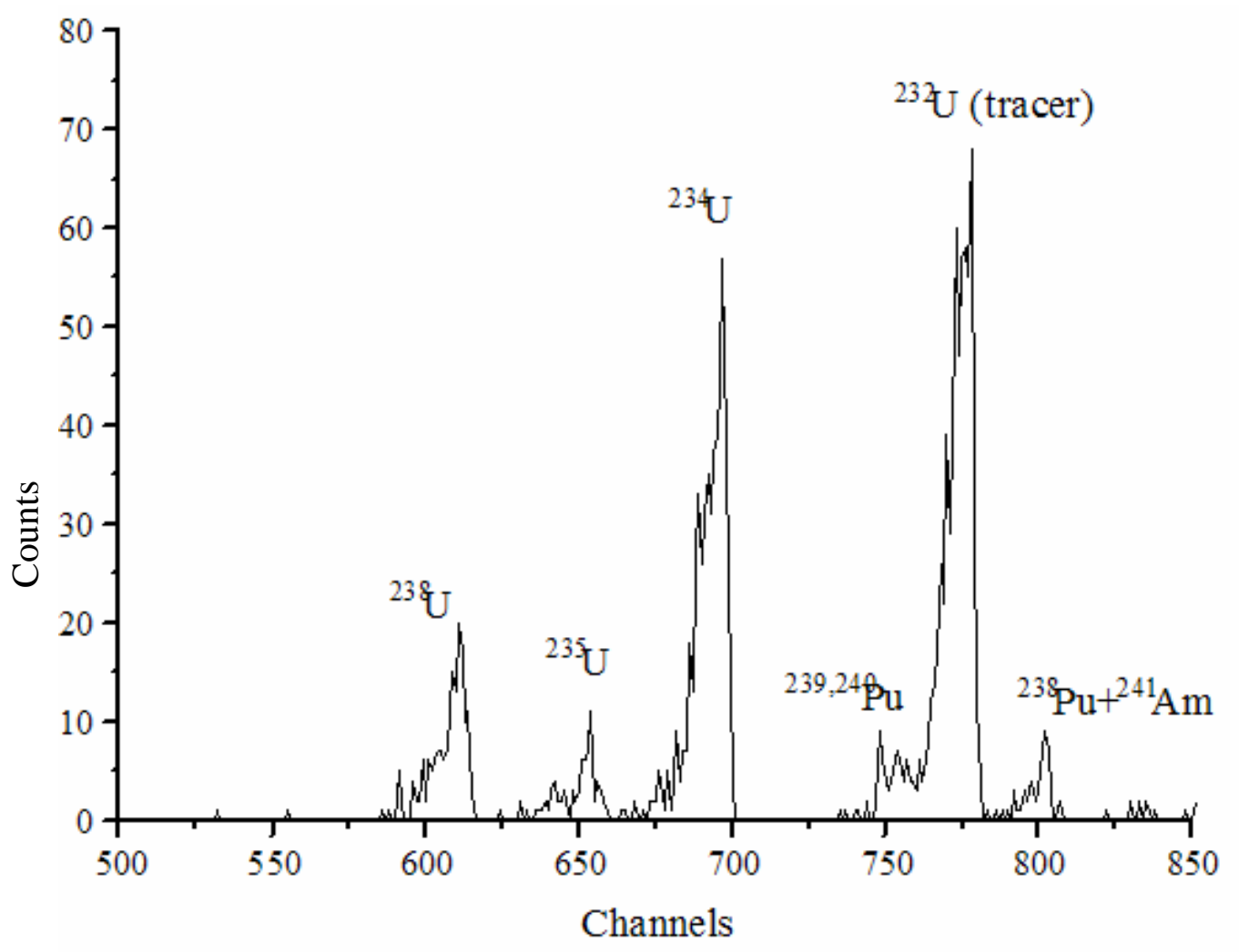

Fig. 4. Alpha spectrum of uranium isotopes after separation using the UTEVA ion exchange resin. 


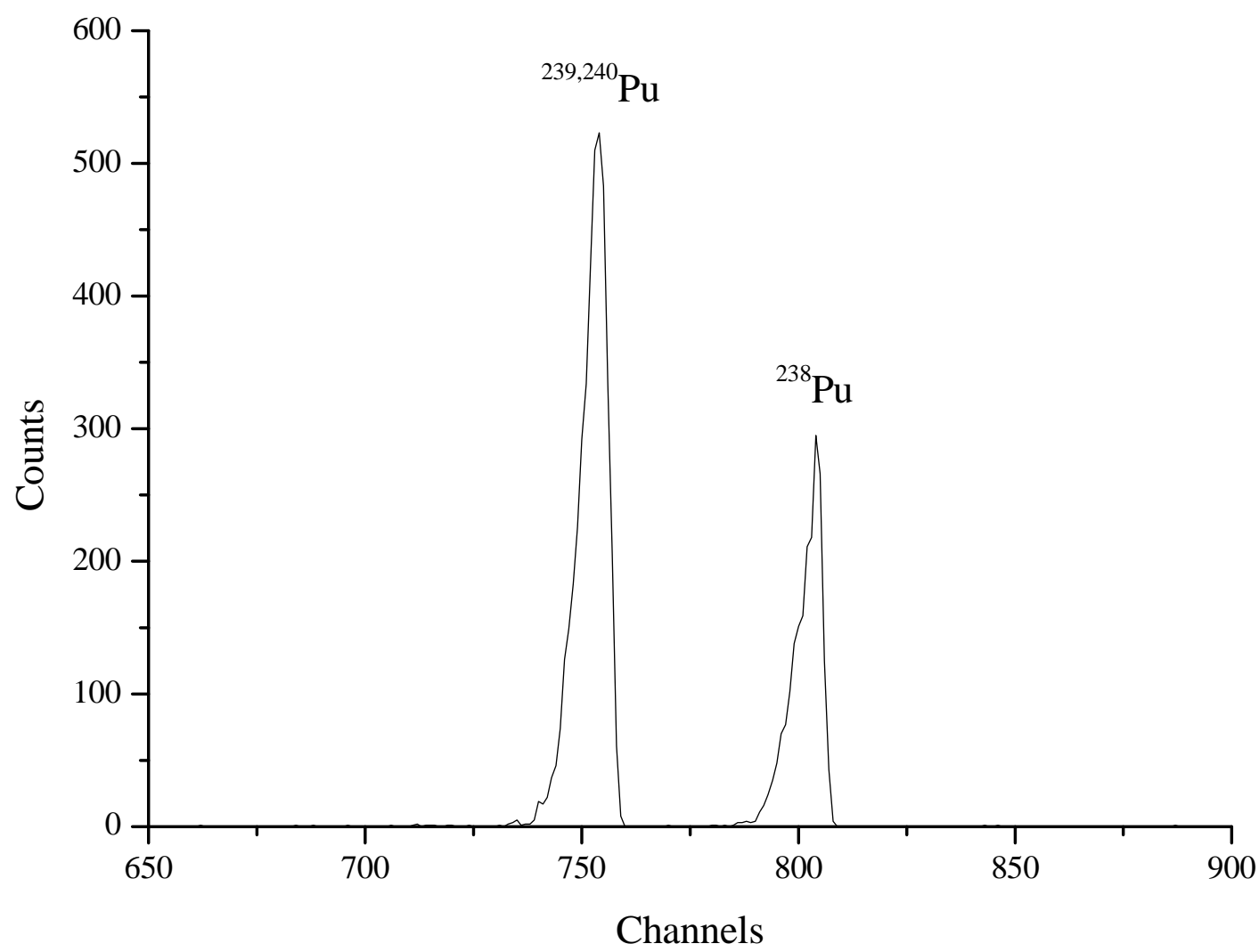

Fig. 5. Alpha spectrum of plutonium isotopes after separation using UTEVA ion exchange resin. 


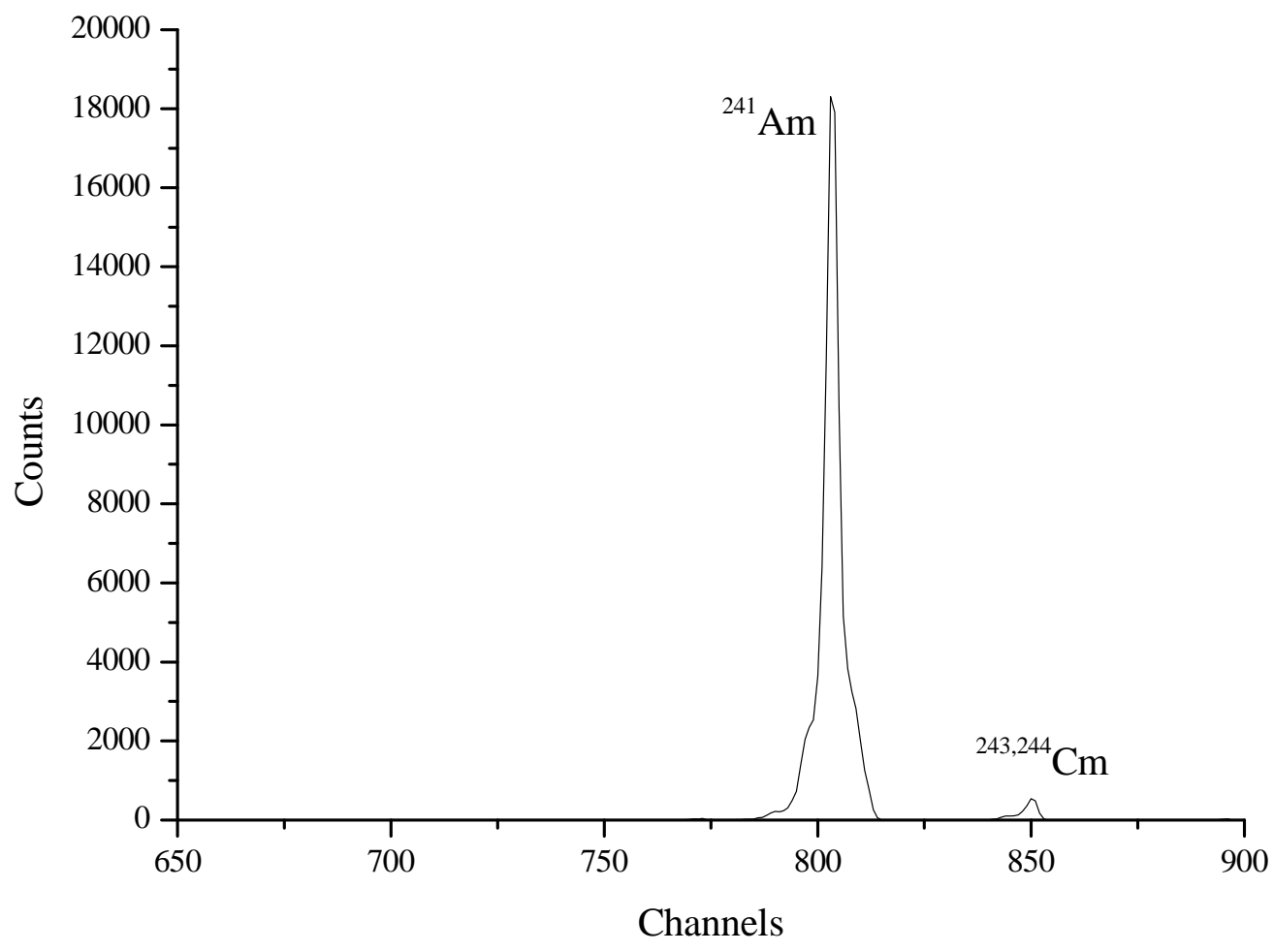

Fig. 6. Alpha spectrum of americium and curium after separation using UTEVA and TRU ion exchange resins. 




Fig. 7. Fragments of the Samples Gamma Spectra Obtained by Using the Gamma Gamma Coincidence System with a Large NaI (Tl) Detector and a HPGe Detector (a - single spectrum). 




Fig. 7. Fragments of the Samples Gamma Spectra Obtained by Using the Gamma Gamma Coincidence System with a Large NaI (Tl) Detector and a HPGe Detector (b - coincidence spectrum). 
Table 1. Specific activities of radionuclides in a ChNPP fuel particle analyzed by gamma and radiochemical methods.

\begin{tabular}{cc}
\hline Isotope & $\begin{array}{c}\text { Specific activity of a particle, } \\
\text { Bq g }\end{array}$ \\
\hline${ }^{137} \mathrm{Cs}$ & $5.79 \times 10^{6}$ \\
${ }^{154} \mathrm{Eu}$ & $1.01 \times 10^{5}$ \\
${ }^{241} \mathrm{Am}$ & $4.79 \times 10^{5}$ \\
${ }^{90} \mathrm{Sr}$ & $1.57 \times 10^{7}$ \\
${ }^{234} \mathrm{U}$ & $4.79 \times 10^{2}$ \\
${ }^{235} \mathrm{U}$ & $6.30 \times 10^{1}$ \\
${ }^{238} \mathrm{U}$ & $1.71 \times 10^{2}$ \\
${ }^{242} \mathrm{Pu}$ & $7.57 \times 10^{2}$ \\
${ }^{239,},{ }^{240} \mathrm{Pu}$ & $3.09 \times 10^{5}$ \\
${ }^{238} \mathrm{Pu}$ & $1.52 \times 10^{5}$ \\
${ }^{236} \mathrm{Pu}$ & $8.40 \times 10^{1}$ \\
${ }^{241} \mathrm{Pu}$ & $5.76 \times 10^{6}$ \\
${ }^{243} \mathrm{Am}$ & $1.02 \times 10^{3}$ \\
${ }^{241} \mathrm{Am}$ & $5.19 \times 10^{5}$ \\
${ }^{243} \mathrm{Cm}$ & $1.13 \times 10^{4}$ \\
${ }^{244} \mathrm{Cm}$ & $1.20 \times 10^{3}$ \\
${ }^{242} \mathrm{Cm}$ & $5.65 \times 10^{2}$ \\
\hline
\end{tabular}


Table 2. Fuel burnup ( \pm error) calculated using isotopic ratios.

$$
\left[\mathrm{MW} \cdot \text { day } \mathrm{kg}^{-1}(\mathrm{U})\right] \text {. }
$$

\begin{tabular}{cccc}
\hline Sample & Eu & Cs & Pu \\
\hline Hot Particle \# 1 (min. activity) & $12.6( \pm 0.5)$ & $10.3( \pm 0.2)$ & $12.9( \pm 0.2)$ \\
Hot Particle \# 2 (max. activity) & $13.6( \pm 0.5)$ & $9.7( \pm 0.3)$ & $13.3( \pm 0.2)$ \\
\hline
\end{tabular}

